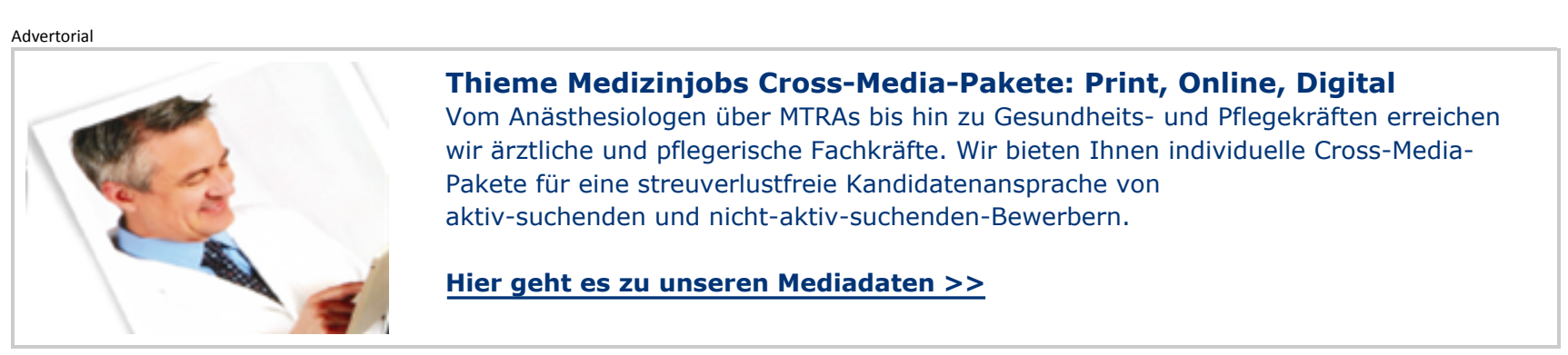

Share / Bookmark

Planta Med 2014; 80 - P2B26

DOI: $10.1055 / \mathrm{s}-0034-1394903$

\title{
Individual phenolic profile and antioxidant activity of vegetative parts from cultivated or wild growing Fragaria vesca $L$.
}

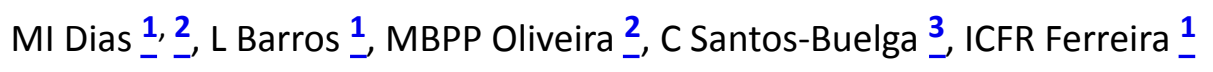

- ${ }^{1}$ Mountain Research Center (CIMO), ESA, Polytechnic Institute of Bragança, Portugal

- ${ }^{2}$ REQUIMTE, Science Chemical Department, Faculty of Pharmacy, University of Porto, Portugal

- ${ }^{3}$ GIP-USAL, Facultad de Farmacia, Universidad de Salamanca, Spain

- $\underline{\text { Congress Abstract }}$

Fragaria vesca L. (Rosaceae), wild strawberry, is widely spread across the Iberian Peninsula and can be also found in Korea, Japan, North America and Canada. Usually it grows in forests, slopes and roadsides [1]. The leaves are traditionally used as tonic, stimulant and diuretic, described are also antiseptic, antidysenteric and detoxifying properties; the decoction is also used for hypertension [2, 3]. The bioactive properties of Fragaria have been associated with the presence of ellagic acid, procyanidins and flavonols, as previously described for leaves of F. chiloensis spp. chiloensis [4]. As far as known, there are no reports on the phenolic profile of vegetative parts of $F$. vesca. Therefore the phenolic profile and the antioxidant potential were studied with hydro-methanolic and aqueous extracts of vegetative parts of cultivated and wild grown $F$. vesca. Both samples contained ellagic acid derivatives and sanguiin $\mathrm{H}-10$ isomer as the major compound, followed by a procyanidin trimer and quercetin rhamnoside in cultivated and wild grown plant material, respectively. The cultivated plant material showed higher DDPH scavenging activity $\left(\mathrm{EC}_{50}=39.33 \mu \mathrm{g} / \mathrm{mL}\right)$ and had more total phenolic compounds (TPC) $(58.73$ $\mathrm{mg} / \mathrm{g}$ ) than the wild grown sample. The antioxidant capacity of the cultivated plant material (especially reducing power and $\beta$ - carotene bleaching inhibition) showed high correlation with the content of total ellagic acid derivatives (TED), total flavonols (TF), total flavan 3-ol (TF3O) and TPC. In contrast, wild grown sample infusions showed higher reducing power, $\beta$-carotene bleaching inhibition and TBARS inhibition ( $E C_{50}=62.23,12.34$ and $3.12 \mu \mathrm{g} / \mathrm{mL}$, respectively); reducing power showed high correlation with TF and TF3O, and TBARS assay with TED and TF. Data obtained show a great antioxidant potential of vegetative parts from wild growing strawberry, which might be a new source of bioactive compounds for 
food and pharmaceutical applications.

References:

[1] Castroviejo, S., Aedo, C., Cirujano, S., Laínz, M., Montserrat, P., Morales, R., Muñoz Garmendia, F., Navarro, C., Paiva, J. \& Soriano, C. (eds.). Flora ibérica, 6th ed.,; Real Jardín Botánico CSIC: Madrid, 1998.

[2] Camejo-Rodrigues, J., Ascensão, L., Bonet, M. À., Vallès, J., Journal of Ethnopharmacology, 2003, 89, $199-209$.

[3] Neves J.M., Matos, C., Moutinho, C., Queiroz, G., Gomes, L.R., Journal of Ethnopharmacology, 2009, $124,270-283$.

[4] Simirgiotis, M.J., Schmeda-Hirschmann, G., Journal of Food Composition and Analysis 2010, 23, 545 553.

Top of Page

(C) 2018 Georg Thieme Verlag KG | Impressum I Privacy | Smartphone Version 